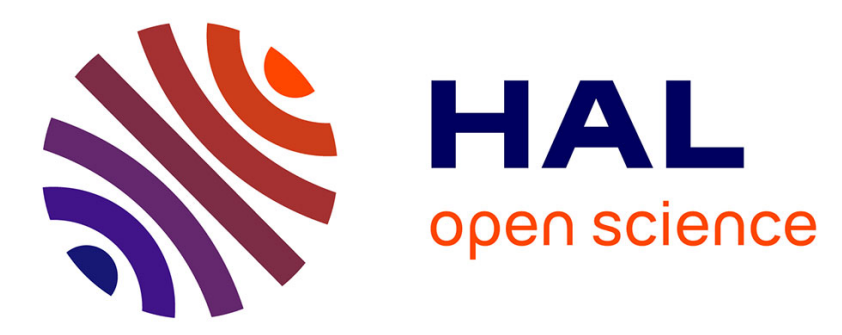

\title{
Source-sink relationships vary with age in Chinese pine (Pinus tabulaeformis Carr.): analysis using the GreenLab model
}

Hong Guo, Veronique Letort, Yuanchang Lu, Jun Diao, Philippe de Reffye

\section{- To cite this version:}

Hong Guo, Veronique Letort, Yuanchang Lu, Jun Diao, Philippe de Reffye. Source-sink relationships vary with age in Chinese pine (Pinus tabulaeformis Carr.): analysis using the GreenLab model. 2012 IEEE 4th International Symposium on Plant Growth Modeling, Simulation, Visualization and Applications, Oct 2012, Shanghai, China. pp.148-151, 10.1109/pma.2012.6524826 . hal-00781173

\section{HAL Id: hal-00781173 \\ https://hal-centralesupelec.archives-ouvertes.fr/hal-00781173}

Submitted on 25 Jan 2013

HAL is a multi-disciplinary open access archive for the deposit and dissemination of scientific research documents, whether they are published or not. The documents may come from teaching and research institutions in France or abroad, or from public or private research centers.
L'archive ouverte pluridisciplinaire HAL, est destinée au dépôt et à la diffusion de documents scientifiques de niveau recherche, publiés ou non, émanant des établissements d'enseignement et de recherche français ou étrangers, des laboratoires publics ou privés. 


\section{Source-sink relationships vary with age in Chinese pine (Pinus tabulaeformis Carr.): analysis using the GreenLab model}

\author{
Hong Guo ${ }^{1}$ Yuanchang $\mathrm{Lu}^{2}$ Jun Diao ${ }^{3}$ \\ Research Institute of Forest Resource Information \\ Techniques \\ Chinese Academy of Forestry Beijing, China,100091 \\ 1 hongguo@caf.ac.cn \\ 2 ylu@caf.ac.cn \\ 3 d03040110@163.com
}

\author{
Véronique Letort \\ Applied Mathematics \& Systems Laboratory \\ Ecole Centrale Paris, Chatenay-Malabry, 92290 France \\ veronique.letort@ecp.fr \\ Philippe de Reffye \\ CIRAD, UMR AMAP, Montpellier, F-34000 France \\ dereffye@cirad.fr
}

\begin{abstract}
Tree growth and development rely on the underlying dynamics of their source-sink balance. Given the difficulty of collecting experimental data on adult trees, models can be used as tools to disentangle the complex processes that drive biomass production and allocation. This paper investigates the variations of parameters with age driving the source-sink balance of individual trees through the functional-structural plant model GreenLab. Six Chinese pine (Pinus tabulaeformis Carr.) trees were destructively sampled and were divided into three groups based on ages: 5-year old, 10-year old and 18-year old. Firstly, the effects of age on organ dimensions and on organ relative mass were analyzed based on direct experimental measurement. Secondly, the hidden parameters of the GreenLab model were estimated using the data of total tree biomass for needle and wood compartment independently and then for the six trees in parallel. The statistical tests showed that there were significant differences between the tip attributes on first-, second-, and third-order branches of the three age stages for internode diameter, internode sink and needle sink. Preliminary fitting results showed that the sink of layers and the parameter of biomass production efficiency $1 / r$ decrease with age.
\end{abstract}

Keywords- functional-structural plant model, source-sink relationship, age effect, pinus tabulaeformis

\section{INTRODUCTION}

Tree growth and development rely on the underling dynamics of their source-sink balance that drive the processes of biomass production and allocation to the different compartments of tree growth. Analyzing their variations with age throughout the tree life span can help better understanding of tree mortality, recruitment, growth, and yield all of which are critical for forest management and conservation. Empirical models are classically used to calculate increments of diameter and height to get the tree growth dynamics and to calculate the rate of biomass allocation in different organ types [1]. It is known that allocation of biomass to individual tree components changes over the life cycle of a forest [2]. But empirical models usually only consider global characteristics at different age stages. The lack of description of physiological processes and of crown structure development makes it difficult to get detailed source-sink parameters in different organ types and to study their variations at different age ages. Functional structural plant models (FSPMs) which combine physiological process and morphological development provide a tool to analyze tree growth and development. FSPMs have been applied to simulate individual tree growth, e.g.: LINGUM model [3] and L-Peach model [4]. GreenLab is a generic FSPM describing source-sink relationship within the tree to simulate biomass production and allocation. The growth rate is computed from leaf area and the biomass partitioning is governed by the sink strength, which means the capability to acquire biomass for organs, of growing individual organs present in plant structure [5][6]. The parameters of GreenLab have been estimated for Chinese pine [7][8], beech[9], Scots pine [10]. But these studies were performed with the objective of finding a unique set of parameters to fit all the target trees and the hypothesis of parameter dependence on age was not considered.

The objectives of this study are: 1) to examine the statistical differences of the partitioning of above ground tree component biomass at both global and organ levels point of view in relation to tree age; 2 ) to get and compare the sourcesink factors for aboveground tree components at different age stages through the calibration of GreenLab.

\section{MATERIALS AND METHOD}

\section{A. Source-sink model}

The GreenLab tree model was described in detail in [8]. Here, we simply recall the necessary source-sink equations and parameters are listed as follows. Time is discredited a step of one year, also called Growth Cycle (GC).

The biomass production at GC i can be described as:

$$
Q(i)=S_{d}\left(1-\exp \left(-S(i) / S_{d}\right)\right) / r
$$

$Q(i)$ is the total biomass production at GC $i, S(i)$ is the total leaf surface area at GC $i, 1 / r$ is a factor of biomass production efficiency, and $S_{d}$ (in $\mathrm{m}^{2}$ ) is a characteristic surface area that drives the tree maximal potential production. At each GC, the carbon production is partitioned between all growing parts of the tree according to a model of proportional sink competition. Biomass is 
allocated between the two main compartments of tree growth: primary growth, which consists in the creation of new phytomers and elongation of internodes and needles, and secondary growth, corresponding to the increase in branch diameter.

The sink of new organs $P_{o}(k)$ depends on their branching order or PA(physiological age)[7]. The biomass allocated to organ $o$ of PA $k$ at GC $i \Delta q_{o}(i, k)$ is proportional to the ratio of available biomass $Q(i)$ to the plant total demand $D(i)$ which is the sum of demands of new organs and of demand of rings $D_{r g}(i)$ :

$$
\begin{aligned}
& \Delta q o(i, k)=P o(k) \times Q(i) / D(i) \\
& D(i)=\sum_{o} \sum_{k} N_{o}^{\prime}(k, i) \times P_{o}(k)+D_{r g}(i)
\end{aligned}
$$

Where $Q(i)$ is the total biomass production at GC $i, D_{r g}(i)$ is the demand of rings at GC $i$ and $o$ represents indices for organ types (needles: $a$; internodes: $e$ ). $N_{o}^{\prime}(k, i)$ is the number of new organs belonging to category $o$ of PA $k$ and appearing at GC $i$. The demand of the compartment for secondary growth $D_{r g}$ is defined based on the consideration of the widespread use of the pipe model [12] which implies that the cambial growth is correlated to the number of living leaves. Therefore, the ring demand $D_{r g}(i)$ is modelled as:

$$
D_{r g}(i)=P_{r g} \times N_{a}(i)
$$

Where $P_{r g}$ is the sink parameter (per mass unit, $\mathrm{g}^{-1}$ ) of the ring compartment, and $N_{a}(i)$ is the total number of needles (considering all the needles of the virtual phytomer as one) of the plant at GC $i$. Note that, in contrast to [8], the ratio of biomass supply to demand is not included in the equation of ring demand: this hypothesis was confronted to the data and this term was found not influential in the estimation procedure and was thus neglected.

Biomass is allocated to the ring compartment proportionally to its demand $D_{r g}(i)$. Then it is partitioned into every living phytomer according to their position in the tree topological structure. This partitioning is driven by a parameter $(0<\lambda<1)$ : as detailed in [9], it is based on a generalization of the Pressler law [13] that states that annual ring increment of a phytomer is proportional to the foliage quantity located above it. The parameter $\lambda$ drives the relative influence of the number of needles on the cambial growth: if $\lambda=1$, the partitioning follows the Pressler law while if $\lambda=0$, the cambial growth is uniform whatever the position of the phytomer relatively to foliage is.

Finally, internode length is computed from internode mass using the following allometric relationship, that involves two parameters $a$ and $b$ :

$$
l(k, o, i)=a \times q(k, o, i)^{b}
$$

Where $o$ denotes the chronological age of the tip, $a$ and $b$ are shape coefficients fitted from lengths and fresh weights of the new created phytomers, assuming here that pith wood density is constant.

\section{B. Tree materials}

Six Chinese pine trees were selected in November 2009 from the nursery garden located in the Yuanyiqi forest farm,
Beijing, China. Two 5-year-old trees (T1 and T2), two 10year-old trees (T3 and T4) and two 18-year-old (T5 and T6) trees were selected with average rules.

These six selected trees were felled to measure their topological structure and organ mass and dimensions. The reproductive organs were not considered in the study since their biomass was negligible for these trees. Detailed measurements on whole tree at organ scale are experimentally costly, thus the following sampling strategy was adopted. At each whorl and each branching order, we sampled one representative branch, subjectively chosen as an average branch of the whorl. For each phytomer on the selected branch, its length, diameter, fresh woody biomass and fresh needle biomass were measured. For the remaining branches, we measured the total fresh mass of wood and needles.

The observed life span for needles was 3 years. Totally 662 branches were sampled

\section{DATA ANALYSIS}

\section{A. Global characteristics of the six measured trees}

The characteristics attributes (height, biomass, basal diameter, average crown radius of trees) of trees at three age stages are presented in Table 1 that the Linear regression was done between two attributes such as age and height, age and total weight, age and basal diameter.

\section{B. Statistics of the attributes of terminal shoots}

For the three age-groups, there is a statistically significant difference among the three branch order groups $(\mathrm{P}=<0.001)$, as shown by Kruskal-Wallis test [14] and between any group and the other group, as shown by All Pairwise Multiple Comparison Procedures (Dunn's Method). The average values of internode biomass, internode length, internode diameter and needle biomass decrease with branch order at all age stages.

Because of different sample numbers of groups, to isolate groups at different age stages that differ from the others, we use Dunn's Method. The results showed that, between 5-year old trees and 18-year old trees, significant differences are found for internode mass, internode length, internode diameter and needle mass of second-order tips and third-order tips in terminal shoots between 10-year old and 18-year old trees, significant differences are found for internode mass, internode length and needle mass of secondorder tips and third-order tips. Between 5-year old trees and 10 -year old trees, no significant differences were found for any of the measured variables.

\section{PARAMETERS OF SOURCE-SINK GREENLAB MODEL}

\section{A. Analysis of sink ratio}

To understand the changes in biomass allocation for primary growth at different age stages, we performed linear regressions of the biomass of internodes to that of needles of living terminal shoot on the first-order, second-order and third-order branches. The coefficients of determination $R^{2}$ 
ranges from 0.62 to 0.93 except first-order branches for 18year old trees $\left(R^{2}=0.37\right)$ at three age stages $(\mathrm{P}<0.0001)$, which reveals that there is a strong linear relationship between needle mass and internode mass of terminal shoots for each PA (see Table 2). This property is transferred into the model by defining constant sink strength coefficients for internodes and needles. It is significantly different for internode-needle biomass ratio among three age stages.

\section{B. Analysis of internode allometries}

From the measurement of fresh mass and length of internodes of terminal shoots with each PA (where secondary growth can be considered as negligible), the parameters $a$ and $b$ of equation (5) can be estimated for each PA according to the allometry equation between internode biomass and internode length of terminal shoots [7]. The coefficients of determination $R^{2}$ ranged from 0.78 to 0.96 (Figure 1). The difference between the parameter $a$ of the allometry relationship is significant (Dunn's Method, $\mathrm{p}<0.0001$ ) at 3-age stages for each PA. For parameter $a$, it decreased with ages, while parameter $b$ factor had no significant difference at different ages and at different PA.

\section{Hidden parameters of the model}

Six target files were produced from the complete description of each tree. Using the generalized non-linear least squares method [15], firstly we estimated the parameters of the model for each tree independently. The topology of each tree is set as the observed one, following the procedure presented in [8]. The sink strengths and the allometry parameters are input for each tree age and each branching order. Therefore, the only parameters that need to be estimated are the biomass production efficiency $(1 / r)$, the sink of layer $\left(P_{r g}\right)$ and the parameter for ring increment $(\lambda)$. The first two can be estimated on compartment data only since they have no influence on the partitioning phase at individual metamer level. Table 3 displays the parameter estimates. Given the low number of data ( 2 for each tree), the coefficients of variation are very high and the significance of the differences cannot be properly tested. It nevertheless reveals that the sink of rings and the parameter of biomass efficiency decreases with age. Since the values of the variation coefficient for $P_{r g}$ are very high, we also tested the estimation of a unique value of $P_{r g}$ for all trees in parallel. Results are given in Table 3 . It confirms the observed tendency of decrease of $1 / r$ values with age. Differences were tested with the Student $t$ test for unequal variance (Welch-Satterthwaite statistic) and were found significant between the age-groups.

\section{CONCLUSION}

The results of this study suggest a significant effect of age on internode allometry (determining internode geometrical dimensions) and source-sink parameters of GreenLab model. We list the main findings as follows:
The directly measured variables: internode mass, internode length and needle mass of tip shoots are found significantly different between 10 year-old and 18 year-old trees but not between 5 year old and 10 year-old trees.

There are significant differences for allometric parameter $a$, which is decreasing with ages. And $a$ is decreasing with branching order for 5-year old and 10-year old trees. There are not significant differences for allometric parameter $b$.

Preliminary fitting results showed that the sink of layers and the parameter of biomass production efficiency $1 / r$ decrease with age.

However, the main limitation of our findings is the limited number of trees and the lack of age replications in different conditions.

\section{ACKNOWLEDGMENT}

We are grateful to Cournède Paul-Henry's help for Digiplante software, and Lei Xiangdong, Rong Jiantao, Liu Xianzhao from Chinese Academy of Forestry (CAF) for their contributions to field observations. The study was supported by Natural Science Foundation of China (No.31100474) and Zhejiang Tengtou Landscape Co. LTD.

\section{REFERENCES}

[1] T. Satoo , H.A.I Madgwick, Forest Biomass. M. Nijhoff/Dr. W. Junk Publishers, Boston, 1982, 152 pp.

[2] H.S. Helmisaari, K. Makkonen, S. Kellomaki, E. Valtonen, E. Malkonen. Below- and above-ground biomass, production and nitrogen use in Scots pine stands in eastern Finland. Forest Ecol. Manage. 2002, 165, 317-326.

[3] J. Perttunen, R. Sievänen, E. Nikinmaa, et al. LIGNUM: A Tree Model Based on Simple Structural Units, Annals of Botany, 1996, 77: 87-89.

[4] M.T. Allen, P Prusinkiewicz and T.M. Dejong, "Using L-systems for modeling source-sink interactions, architecture and physiology of growing trees: the L-PEACH model”. New Phytologist, 2005, 166 (3), 869-880.

[5] P. de Reffye, T. Fourcaud, F. Blaise, D. Barthèlèmy, F. Houllier. A functional model of tree growth and tree architecture. Silva Fennica, 1997,31: 297-311.

[6] M.Z. Kang, P.H. Cournède, P. de Reffye, D. Auclair, B.G. Hu, Analytical study of a stochastic plant growth model: Application to the GreenLab model Mathematics and computers in simulation, 2008, 78 (1): $57-75$.

[7] H. Guo, V. Letort, L.X. Hong, T. Fourcaud, P.H. Cournède, Y.C. Lu, P. de Reffye. Adaptation of the GreenLab model for analyzing sinksource relationships in Chinese pine saplings, In: Second international symposium on plant growth modeling and application, 2006. PMA'06, IEEE, Beijing, pp 236-243.

[8] H. Guo, X.D. Lei, P.H. Cournède, V. Letort. Characterization of the effects of inter-tree competition on source-sink balance in Chinese pine trees with the GreenLab model. Trees Structure and Function, 2012, 26(3): 1057-1067.

[9] V. Letort, P.H. Cournède, A. Mathieu, P. de Reffye and T. Constant Parametric identification of a functional-structural tree growth model and application to beech trees (Fagus sylvatica). Functional plant biology,2008, 35: 951-963.

[10] F. Wang, M.Z. Kang, Q. Lu, V. Letort, H. Han, Y. Guo, P. de Reffye, B.G. Li.A stochastic model of tree architecture and biomass 
[11] partitioning: application to Mongolian Scots pines. Annals -of Botany, 2011,107:781-792.

[12] R.M. Lanner On the insensitivity of height growth to spacing. For Ecol Manag, 1985, 13:143-148.

[13] K. Shinozaki, K. Yoda, K. Hozumi, T. Kira. A quantitative analysis of plant form—the pipe model theory. I Basic analysis. Jpn J Ecol ,1964,14:97105.

[14] E. Assmann and F. Franz ,Vorläufige Fichten-Ertragstafel für Bayern Forstwissenschaftliches Centralblatt 84 (1/2), Sonderdruck, Verlag Paul Parey, Hamburg and Berlin, Germany, 1965,pp 1-68.W.H. Kruskal and W.A. Wallis "Use of ranks in one-criterion variance analysis", Journal of the American Statistical Association,1952, 47 (260): 583-621.

[15] Cournède PH, Letort V, Mathieu A, Kang MZ, Lemaire S, Trevezas S, Houllier F, de Reffye P (2011) Some parameter estimation issues in functionalstructural plant modelling. Mathematical Modeling of Natural Phenomena 6(2):133-159

TABLE I. C CHARACTERISTICS OF SIX TREES AT 3-AGE STAGES

\begin{tabular}{|c|c|c|c|c|c|c|}
\hline Tree No. & T1 & T2 & T3 & T4 & T5 & T6 \\
\hline Age (year) & 5 & 5 & 10 & 10 & 18 & 18 \\
\hline Height (m) & 1.59 & 1.01 & 2.3 & 2.4 & 4.2 & 3.72 \\
\hline Total weight (kg) & 4.14 & 1.12 & 10.2 & 14.2 & 42.2 & 35.8 \\
\hline Basal diameter (cm) & 6 & 3.5 & 8 & 7.6 & 12 & 10.2 \\
\hline Average crown radius (m) & 0.8 & 0.4 & 1.0 & 1.2 & 2.5 & 2.0 \\
\hline
\end{tabular}

TABLE II. DIRECTLY ESTIMATED PARAMETERS AT 3-AGE STAGES

\begin{tabular}{|c|c|c|c|c|c|c|c|c|c|c|c|c|c|}
\hline Parameter & Description & \multicolumn{12}{|c|}{ Values } \\
\hline & & \multicolumn{4}{|c|}{$Y$} & \multicolumn{3}{|c|}{$M$} & \multicolumn{5}{|c|}{$O$} \\
\hline & & PA1 & PA2 & PA3 & PA4 & PA1 & PA2 & PA3 & PA4 & PA1 & PA2 & PA3 & PA4 \\
\hline$P_{e}$ & Internode Sink & 1.31 & 0.20 & 0.04 & 0.01 & 1.24 & 0.27 & 0.07 & 0.02 & 1.04 & 0.16 & 0.03 & 0.04 \\
\hline$P_{a}$ & Blade Sink & 1.00 & 0.36 & 0.09 & 0.02 & 1.00 & 0.36 & 0.15 & 0.08 & 1.00 & 0.37 & 0.13 & 0.13 \\
\hline$a$ & Slope of Allometry & - & 17.18 & 9.93 & 5.46 & - & 14.56 & 9.66 & 6.29 & - & 13.38 & 9.66 & 3.33 \\
\hline$b$ & Intercept of allometry & - & 0.28 & 0.42 & 0.56 & - & 0.38 & 0.47 & 0.57 & - & 0.63 & 0.53 & 0.70 \\
\hline$S L W$ & Specific leaf weight & & & & & & 0.08 & & & & & & \\
\hline
\end{tabular}

Y denotes 5-year old, M denotes the 10-year old and O denotes 18-year old.

TABLE III. ESTIMATED PARAMETERS VALUES AND THEIR COEFFICIENT OF VARIATION (INTO BRACKETS) AS OBTAINED FROM CONSIDERING EACH TREE AS AN INDEPENDENT TARGET AND THEN FROM ALL TREES TOGETHER.CHARACTERISTICS OF SIX TREES AT 3-AGE STAGES

\begin{tabular}{|c|c|c|c|c|c|c|}
\hline Tree No. & T1 & T2 & T3 & T4 & T5 & T6 \\
\hline$P_{r g}$ & $0.83(2.10)$ & $0.23(2.30)$ & $0.15(1.60)$ & $0.18(1.90)$ & $0.068(1.70)$ & $0.042(1.60)$ \\
\hline$r$ & $0.96(0.60)$ & $0.85(0.30)$ & $2.33(0.50)$ & $2.77(0.40)$ & $5.53(0.40)$ & $5.60(0.30)$ \\
\hline \multicolumn{7}{|c|}{ Parameters estimation for the six trees in parallel } \\
\hline$P_{r g}$ & $1.42(4.20)$ & $1.09(0.90)$ & $3.30(0.30)$ & $3.54(0.20)$ & $6.41(0.07)$ & $5.99(0.10)$ \\
\hline$r$
\end{tabular}
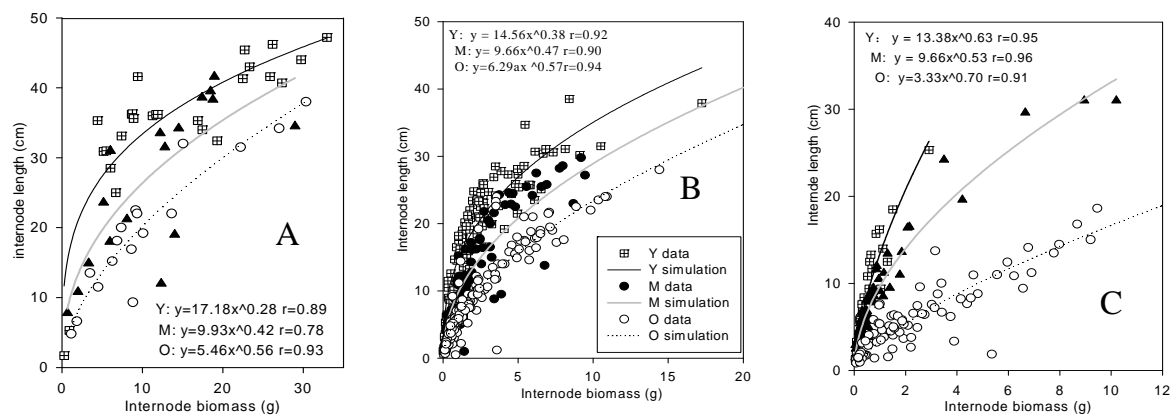

Figure 1. Internode allometry of terminal shoots plotted （A. first-order branches B. second-order branches C. third-order branches ） Y denotes 5-year old, M denotes the 10-year old and $\mathrm{O}$ denotes 18-year old.
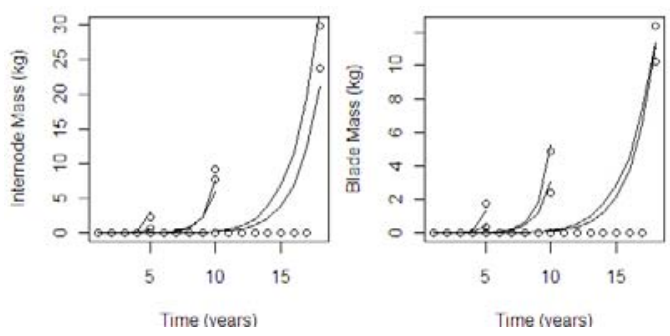

Figure 2. Observed data (dots) and simulated values (lines) of blade and internode compartment biomass for the six trees. 